\title{
The VIADUC project: innovation in climate adaptation through service design
}

\author{
L. Corre ${ }^{1}$, P. Dandin ${ }^{2}$, D. L'Hôte ${ }^{3}$, and F. Besson ${ }^{1}$ \\ ${ }^{1}$ Direction de la Climatologie, Météo-France, Toulouse, France \\ ${ }^{2}$ Centre national de recherches météorologiques (CNRM), Météo-France, Toulouse, France \\ ${ }^{3}$ Strate Ecole de Design, Sèvres, France \\ Correspondence to: L. Corre (lola.corre@meteo.fr)
}

Received: 12 January 2015 - Revised: 20 April 2015 - Accepted: 11 July 2015 - Published: 30 July 2015

\begin{abstract}
From the French National Adaptation to Climate Change Plan, the "Drias, les futurs du climat" service has been developed to provide easy access to French regional climate projections. This is a major step for the implementation of French Climate Services. The usefulness of this service for the end-users and decision makers involved with adaptation planning at a local scale is investigated.

As such, the VIADUC project is: to evaluate and enhance Drias, as well as to imagine future development in support of adaptation. Climate scientists work together with end-users and a service designer. The designer's role is to propose an innovative approach based on the interaction between scientists and citizens. The chosen endusers are three Natural Regional Parks located in the South West of France. The latter parks are administrative entities which gather municipalities having a common natural and cultural heritage. They are also rural areas in which specific economic activities take place, and therefore are concerned and involved in both protecting their environment and setting-up sustainable economic development.

The first year of the project has been dedicated to investigation including the questioning of relevant representatives. Three key local economic sectors have been selected: i.e. forestry, pastoral farming and building activities. Working groups were composed of technicians, administrative and maintenance staff, policy makers and climate researchers. The sectors' needs for climate information have been assessed. The lessons learned led to actions which are presented hereinafter.
\end{abstract}

\section{Introduction}

"Drias, les futurs du climat" service (Lémond et al., 2011) was launched in 2012, as a response of the French scientific community to society's need for climatic information, within the frame of the National Adaptation to Climate Change Plan. The service is mainly composed of a national data website and the associated support. French regional climate projections are easily and freely available. Drias includes general information about the state of the climate system and output from climate modelling. The site also offers users the opportunity to raise question on data access or interpretation, through a dedicated hotline. Lastest advances developed in 2014 include the availability of climate impact data (e.g. water resource, among others), and climate indices based on recent scenarios for socio-economic development (the Representative Concentration Pathways scenarios, used in the 5th IPCC report, 2013). The Volume 4 of "The climate of France for the 21st Century" report entitled "Regionalized scenarios 2014 edition" (Ouzeau et al., 2014) refers to the same climate simulations. Among other results, they show significant rises of averaged temperatures, number of days of summer heat waves, and drought events. Interestingly enough, this update of the reference report has been linked with the Drias service. This will enhance the coherency of various services delivered by the scientific community, which is a key request made by users.

The Drias service has been accompanied by a multidisciplinary users committee. The users feedbacks were very positive and highlighted how the website filled the gap be- 
tween research climate laboratories and society. Yet the committee was mainly composed of advanced users, such as scientists coming from various disciplines (i.e. environmentalists, agronomists, hydrologists, geographers, economists, sociologists, and so forth), and consulting companies involved in environment and policy management, or supporting adaptation administrative entities. Confrontations with non specialist users tell a somewhat different story. The site has been described as a complex tool. In particular, end-users underline their inability to draw any useful conclusion from the huge amount of data available. Moreover, the information delivered to a wide audience seemed highly virtual, and did not meet their principle requirements. This brought up the following question: how can we imagine a service to better support the end-users at large to improve relevant actions for climate adaptation?

\section{Objectives and partners}

The Viaduc project has been set up for 3 years. It is to evaluate and improve the already existing Drias climate service, as well as to imagine future developments by having the scientific community better involved. To address this issue, a team built on the know-how from the Meteorological service (climatologists and climate scientists) and end-users with a service designer was put together. The role of the climate scientists was to present to the users the existing Météo-France deliverables that could meet their needs, and with the designer, to hear their feedback and to develop prototypes that could ultimately feed the production suite.

The chosen end-users are three Natural Regional Parks located in the South West France. Such parks are administrative entities which gather together municipalities defined by a common natural and cultural heritage. They are also rural areas in which economic activities do take place, and therefore are concerned and involved in both protecting their environment and setting up sustainable economic development. Sometimes referred to as adaptation practioners (Lorenz et al., 2015), this category of users is currently under-study, despite being recognized as very much exposed to climate action challenges (Porter et al., 2014).

Between scientists and end-users, the innovative point of the project was to involve a service designer as an interpreter. The service design methodology can be described as the activity of planning and organizing people, infrastructure, communication and material components of the service. The aims were to improve the quality of a service by focusing on the users' needs (e.g. Erlhoff and Marshall, 2008; Stickdorn and Schneider, 2010). Stating that "people have good reason for doing what they do", design considered users' behaviour as the significant consequence of the way they think. Observing and analysing these behaviours allowed pointing-out what does and what doesn't make sense for users. This qualitative diagnostic constituted the basis for the design process

\section{A USER BASED STRATEGY}

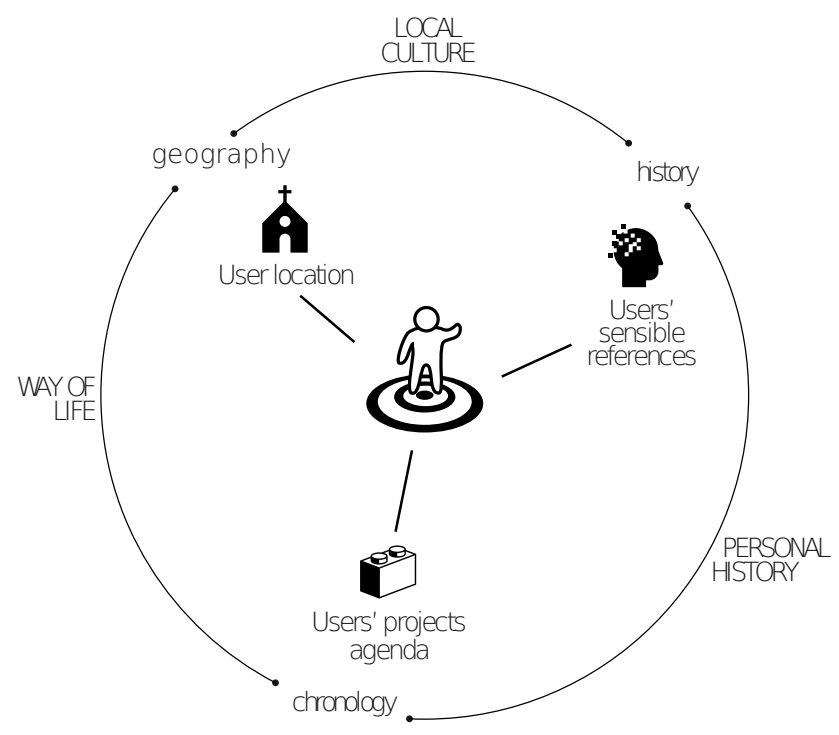

Figure 1. The service design methodology: a user based strategy.

(Fig. 1). Once understood what users considered as meaningful, it became possible to propose and develop solutions that will naturally fit their routines. Within the Viaduc project, the designer was looking for a consensus between the scientific possibilities and constraints and the users' requirements, taking their expectations and references into account. His role thus implied to monitor and ease the dialogue between users and scientists. When the project began, the designer had no theoretical knowledge of climate science.

\section{Undertaken actions}

For the first year of the project, it was decided to work primarily with the task officers in charge of climate action in the Parks. The aim was to understand their plans, abilities, and needs. Progressively, the existing climate adaptation actions were modified and improved: e.g. tailormade exchanges and communications for the local elective representatives, dedicated training for State agents acting locally, and technical working groups with focus on forestry, pastoral farming, and building. Each of these activities corresponds to a priority economical sector in one of the Parks. As an example, in the Haut-Languedoc Park, actions were underway regarding forestry. Working groups gathered experts and scientists from the main French forest and agronomy institutes, local forest technicians and owners, and various actors involved in this economic sector, ranging from regional or local State to companies representatives.

The work progressed with various sectors widely depending on the advancement of the needs identified at the beginning of the project. Thus, foresters had a very precise need of climate data to cross-reference with their own dataset on tree 
evolution (i.e. growth, reddening, among others). The climate scientists simply provided the data, helped to use them and discussed the associated uncertainties. Based on this collaboration, the Institute for Forest Development (IDF) produced a climatic forest atlas as a tool for forest management in the context of climate change (Institut pour le développement forestier/Centre national de la propriété forestière, 2014). In the fields of building and pastoral farming, the identification of needs took much longer. It appeared that the main feedback consisted in a strong need of training for them, expressed by the technical agents who appeared to be the key actors for echoing the climate message.

Beyond supporting actions locally, key messages and lessons which can help the climate research community to improve climate services were delivered. Three important notions have emerged. The first is on the local scale: endusers' involvement appeared to be inversely proportional to their spatial distance from climate change manifestations. The second is on the sector's characteristic time scale: the end-users' awareness appeared to be proportional to the time scales associated with their activity. As tree growth and climate change time scales are both longer than a few decades, foresters are very much exposed to climate change impacts and are already looking for adaptation solutions. On the contrary, pastoral farmers adjust their activity to weather conditions on a daily basis. Not being familiar with long prospects, they were far less responsive to climate scientists warnings. The third important notion concerned impact parameters: to be understood, climate projection need to be translated into sectorial and economical impact parameters. For example, communicating in terms of vegetation sensitivity to summer forest fires, and associated costs, might be more efficient than presenting expected changes through evapotranspiration.

\section{The designer point-of-view}

After one year, the designer delivered a critical report. On the positive side, he highlighted the scientists' transparency and attention to details. On the less positive side, he pointed-out the need to facilitate the appropriation and understanding of the climate projections by users. In his opinion, projections are a research tool made and used by researchers, and most of the time not suitable for non-specialists. Projections mention a changing climate in a too distant future (average time over 30 years) and a too global place (spatial average over the globe, or a whole continent). Moreover, the ensemble of futures that the projections highlighted is more frustrating than satisfying, raising questions instead of providing answers. Projections are depersonalized and decontextualized. Projections are intangible.

As a result of these observations, the designer made some recommendations. First, to make the representation of the scientific results more easily understandable, he suggested to keep to communication standards (style guide). Moreover, figures had to be straightforward and tailored for each category of users. These two points have been already been identified as critical issues to be adressed by the scientific community in order to deliver understandable messages. For example, Kelleher and Wagener (2011) provided ten guidelines for effective data visualisation in scientific publications. Difficulties associated with tailored communication have been analysed by Lorenz et al. (2015). They pointed-out a gap between users comprehension and preferences, as well as a lack of within-users-group homogeneity.

The designer also insisted on the need for narrative process (strorytelling) to accompany scientific figures. The complexity should be introduced progressively, using animations and allowing users to enrich themselves the content. Last but not least, the designer insisted on the necessity of providing a meaningful context. In order to arouse interest, projections need to meet with a personal project (at a given time and space, for a given user). Efficient communication on climate change depended on this timing. The designer suggested taking advantage of windows of opportunity associated with long-term projects, for which people will be concerned with the effects of climate change. He also shed some light on weaknesses of the current service, only delivering future scenarios without any possibility for the users to link this virtual future with known and experienced references. Many clues were lgiven to the scientists in order to help them improve their understanding of the expected products and services they may already deliver for the needs of adaptation.

\section{In practice}

\subsection{Soil moisture in Aveyron: using storytelling}

Let's examine a first attempt to apply the concepts presented above, based on the evolution of the water resources in Aveyron, a French department located near Toulouse, in the MidiPyrénées region. We began with the operational product delivered by Météo-France to water resource managers (Fig. 2). From the latter, this product is very useful, since it allows to place the actual situation in a climatological context (see Dandin et al., 2012). On the contrary, for a wider audience - the task officers involved in the Viaduc project and more than 40 State agents met during trainings - and from the designer's point of view, it was not usable. First attempts were made to improve the products, always bearing in mind that a massive production, able to cover the entire country, must be feasible. Figure 3 shows how animations and storytelling can be used to deliver a clear and striking message of the same scientific material.

This example has been challenged in front of various endusers (i.e. local electives, farmers, among others), and the level of interest was in general very positive. Indeed, its strength consists in anchoring the future in past and present climate references. Past and present situations are stamped in 


\section{Soil moisture index - Aveyron (department 12)}

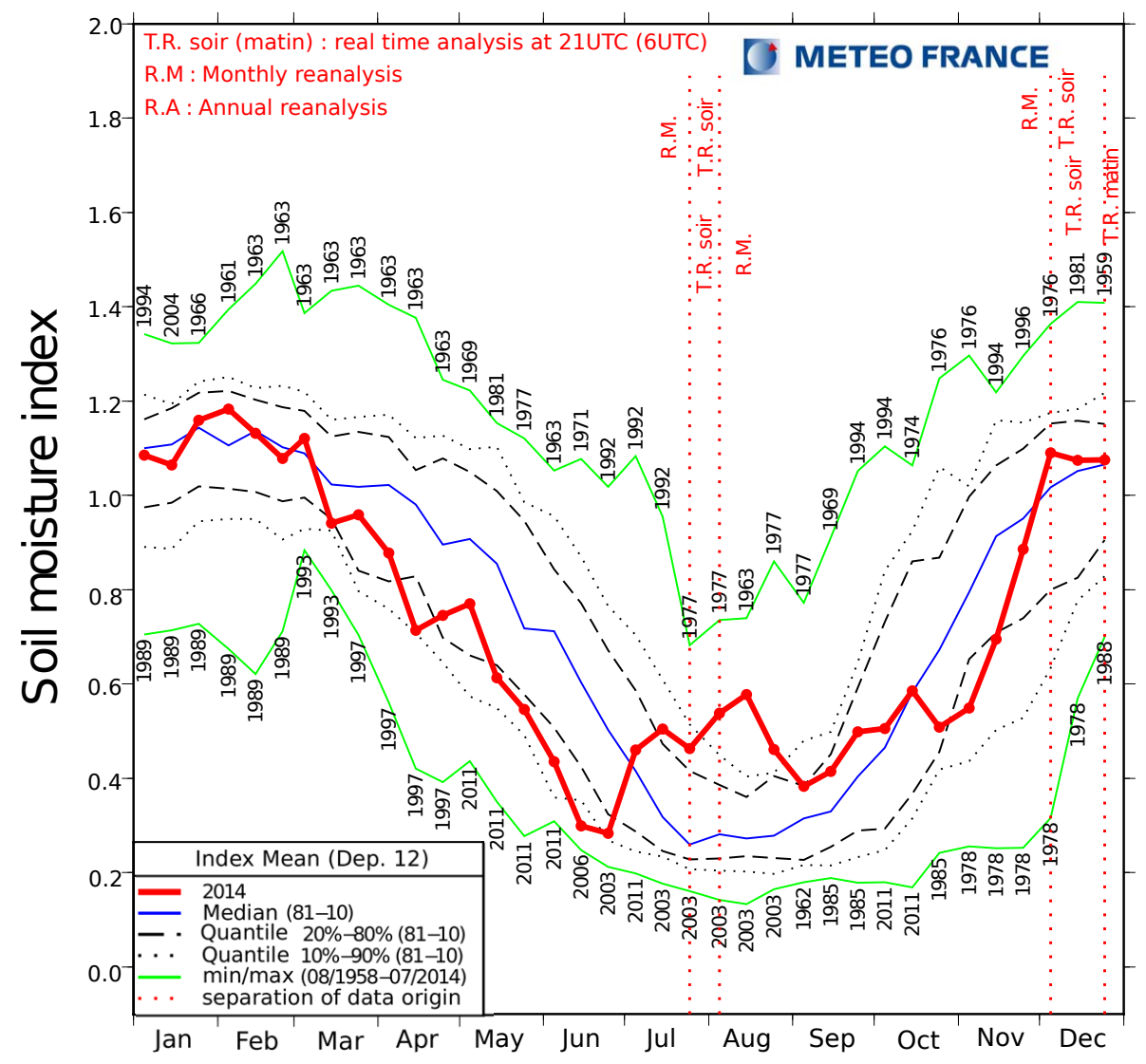

Figure 2. Time sketch showing the evolution of the Soil Moisture Index for a French department (red) in 2014, with climatological reference.

the collective memory and useful for future predictions. Another advantage is that it constitutes a feasible attempt based on an already existing production system. Yet, further developments remain to be done in order to take into account the projections' uncertainties (from multi-models and multiscenarios).

\subsection{Temperature in Clermont-Ferrand: from daily variability to climate change}

Climate change science is based on the detection of longterm changes in mean conditions of climate variables, such as the mean temperature (Hegerl et al., 2007). As they are superimposed with large natural weather-related variability, people in general do not perceive such changes. Several studies suggest that the lack of public concern for climate change is linked with the lack of perception and personal experience of the ongoing changes (Spence et al., 2011; Weber, 2010). When temperature may vary by more than $10^{\circ} \mathrm{C}$ from one day to another at a given place, why should people worry of a long-term $2{ }^{\circ} \mathrm{C}$ global change? Figure 4 is a very preliminary attempt to link the sensible day-to-day weather-related variability with the long-term ongoing climate change. Here the focus is on the summer minimal temperature from a given local weather station (Clermont-Ferrand), between 1960 and 2009. Perceived daily temperature values are represented together with the longer time averages (from monthly to seasonal and decadal values).

\section{Conclusions}

The Viaduc project is a thought-experiment which aims at improving the existing climate services. A dual approach is used, based on supporting actions locally on the one hand, and identifying feasible productions on the other hand. The service design methodology helps sheding light on key messages. Firstly, there is a need to provide local climate information, not only about the future, but also about the past and present. This confirms the strong need for high quality, dense (close) and easily available observations. Secondly, there is a need to communicate in terms of impact. This underlines the need to enhance collaboration with impact communities. Thirdly, the appropriation and understanding of the climate results must be facilitated. This last point is both crucial and difficult, as tailoring the results to each user category pre- 


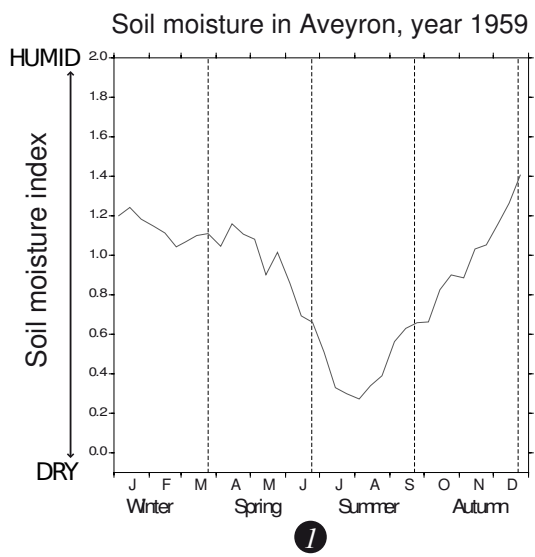

Soil moisture in Aveyron, Observed records 1959-2010 ( $\min , \max )$
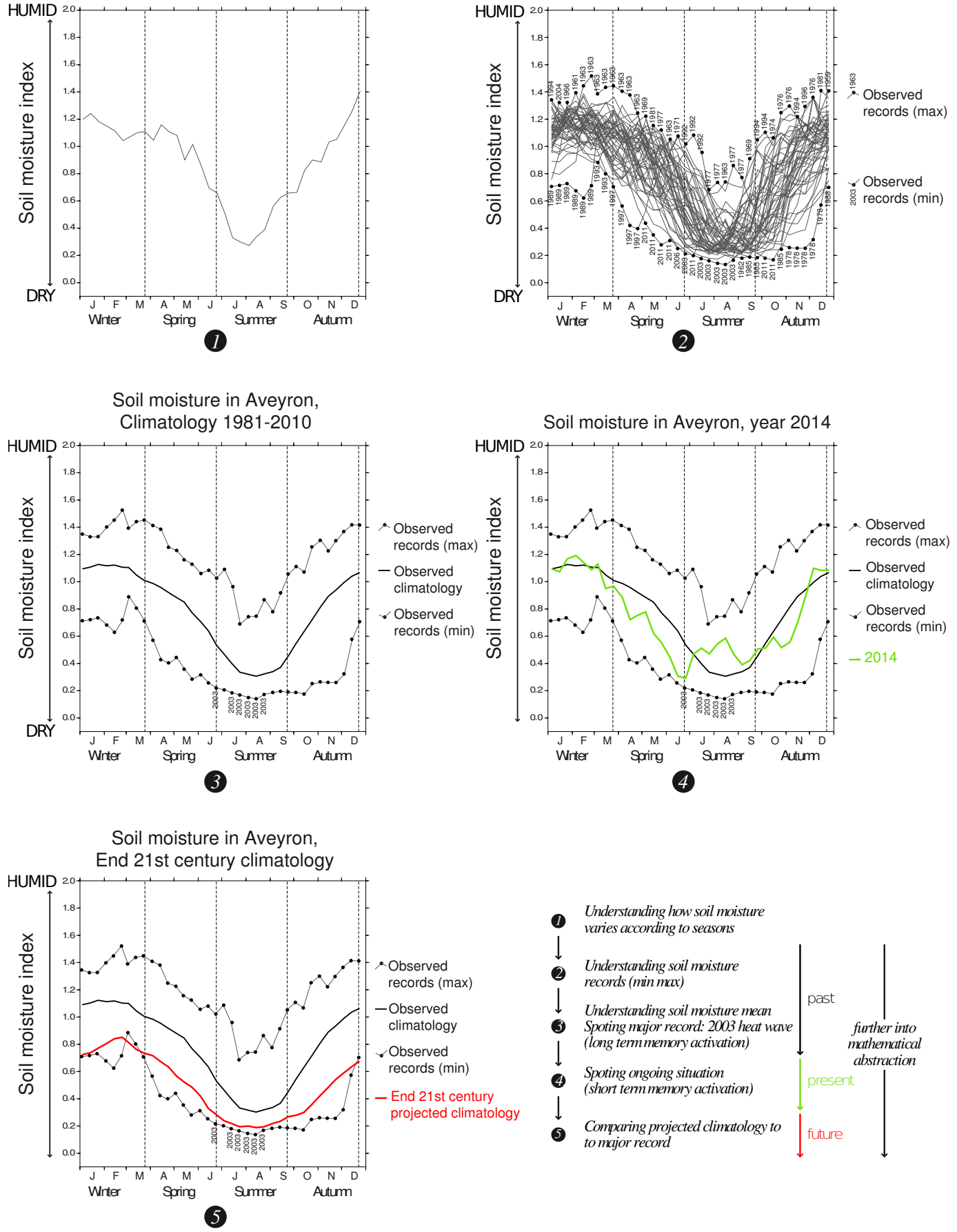

Figure 3. Attempt to ease the understanding of the product presented in Fig. 1, by using animations and storytelling.

vents generalization. Comments guiding the users step-bystep to help them depict the information and understand the message can be easily provided when direct contact is established between producers and users. However, challenges remain (e.g. reports or website products).
Future work will consist in converting the designer theoretical recommendations into feasible productions and prototypes with a view to enrich the Drias services. Many key messages are hidden behind what has been exchanged with end-users during the first year of the project. They bring some sparkle and life to our procedures and old habits. Be- 
(a)

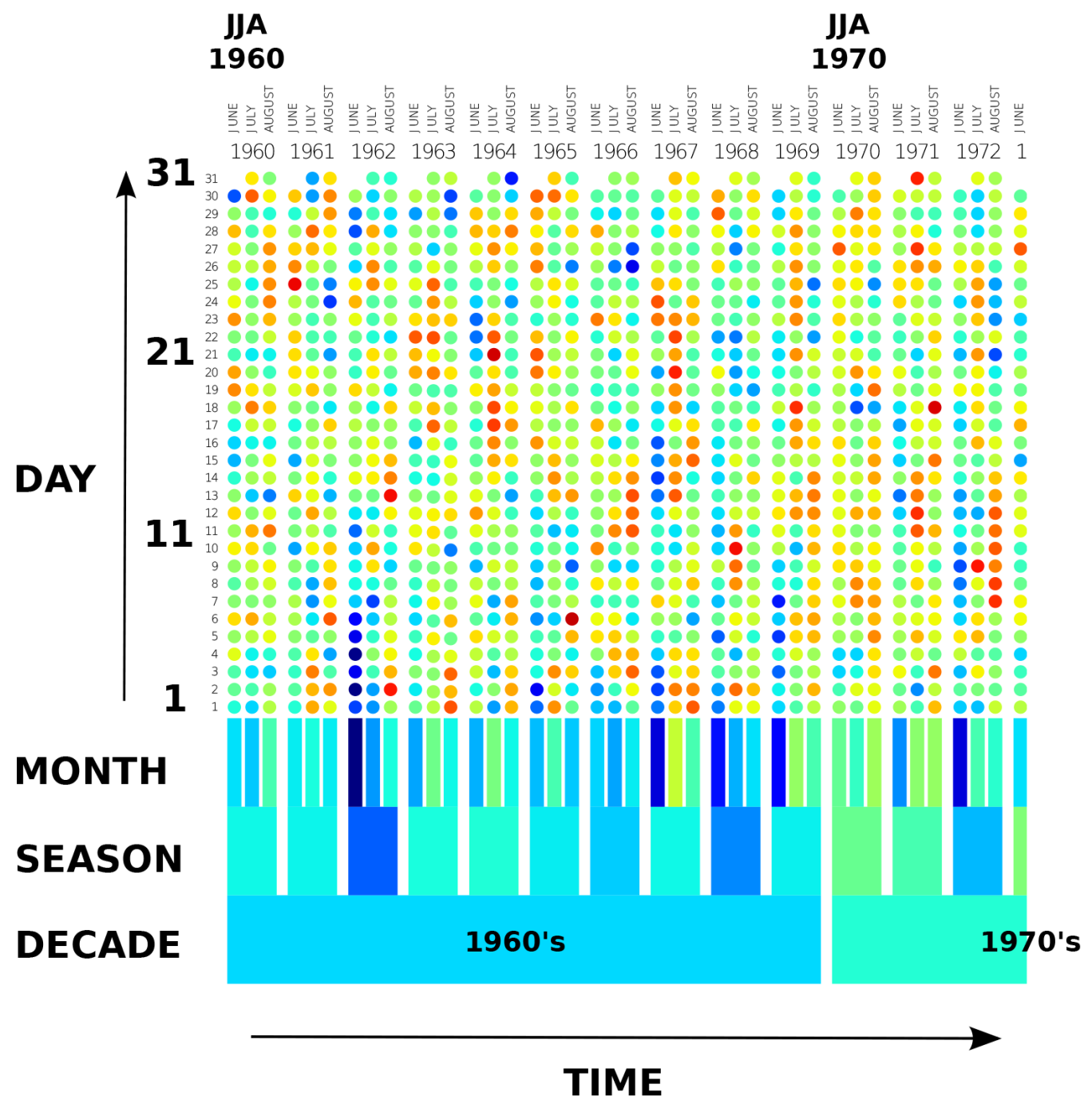

(b)

Temperature in Clermont-Ferrand, summers 1960 to 2009

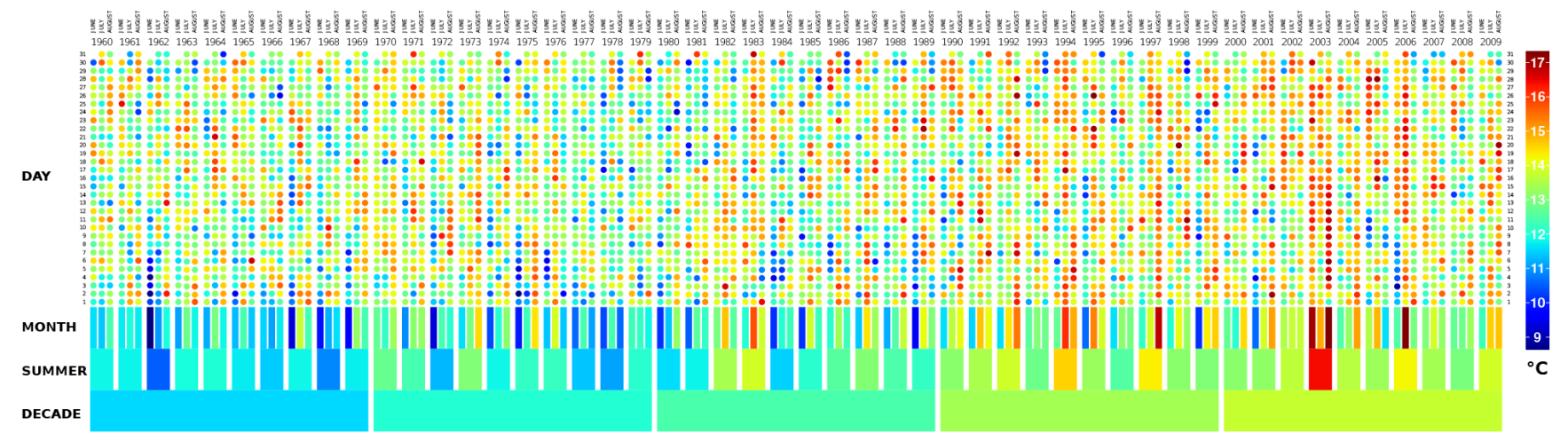

Figure 4. Summer minimal temperature in Clermont-Ferrand. Data are from a new high quality reference dataset (Gibelin et al., 2014) composed of homogenized monthly series and quality controlled daily series. (a) Guidelines on how to read the plot. Colors correspond to temperature values. The upper part of the plot (dots) shows daily temperatures. Each column corresponds to a distinct month (June, July or August). Dots along the vertical show temperatures from day 1 to the last day of the month. The lower part of the plot (rectangles) shows monthly, seasonal and decadal mean temperatures. Each column of dots is averaged and the corresponding monthly mean is shown by an underlying rectangle. Similarly, 3 consecutive monthly means are averaged and the corresponding summer mean is drawn below. Finally, the summer decadal mean is represented using the same color code at the baseline. The time goes from left to right. (b) Summer minimal temperature evolution in Clermont-Ferrand, from 1960 to 2009. 
ing able to transform some of the emerging ideas into real improvements of products and services delivered by the scientific community, to support climate adaptation is a continuing challenge.

Acknowledgements. This work was supported by the MEDDE GICC programme. The authors thank Yves M. Tourre from LDEO of Columbia University for insightful comments.

Edited by: T. Cegnar

Reviewed by: R. Tolasz and two anonymous referees

\section{References}

Dandin, P., Besson, F., Blanchard, M., Céron, J.-P., Franchistéguy, L., Rousset-Regimbeau, F., Soubeyroux, J.-M., Baillon, M., Vidal, J.-P., Singla, S., Martin, E., and Habets, F.: Partnerships on water resource management in France, in: Climate exchange, 2nd Edn., World Meteorological Organization, Geneva, Switzerland, 76-78, 2012.

Erlhoff, M. and Marshall, T. (Eds.): Design Dictionary - Perspectives on design terminology, Birkhaüser Verlag AG, Basel, Germany, 2008.

Gibelin, A. L., Dubuisson, B., Corre, L., Deaux, N., Jourdain, S., Laval, L., Piquemal, J. M., Mestre, O., Dennetière, D., Desmidt, S., and Tamburini, A.: Evolution de la température en France depuis les années 1950: Constitution d'un nouveau jeu de séries homogénéisées de référence, La Météorologie, 87, 45-53, 2014.

Hegerl, G. C., Zwiers, F. W., Braconnot, P., Gillett, N. P., Luo, Y., Marengo Orsini, J. A., Nicholls, N., Penner, J. E., and Stott, P. A.: Understanding and Attributing Climate Change, in: Climate Change 2007: The Physical Science Basis. Contribution of Working Group I to the Fourth Assessment Report of the Intergovernmental Panel on Climate Change, edited by: Solomon, S., Qin, D., Manning, M., Chen, Z., Marquis, M., Averyt, K. B., Tignor, M., and Miller, H. L., Cambridge University Press, Cambridge, UK and New York, NY, USA, 2007.
Institut pour le développement forestier/Centre national de la propriété forestière (Ed.), 2014: Bioclimsol, un outil d'aide à la décision face au changement climatique [Special issue], Forêt entreprise, no. 218, Paris, France, 2014.

IPCC: Climate Change 2013: The Physical Science Basis, in: Contribution of Working Group I to the Fifth Assessment Report of the Intergovernmental Panel on Climate Change, edited by: Stocker, T. F., Qin, D., Plattner, G.-K., Tignor, M., Allen, S. K., Boschung, J., Nauels, A., Xia, Y., Bex, V., and Midgley, P. M., Cambridge University Press, Cambridge, UK and New York, NY, USA, 1535 pp., 2013.

Kelleher, C. and Wagener, T.: Ten guidelines for effective data visualization in scientific publications, Environ. Modell. Softw., 26, 822-827, doi:10.1016/j.envsoft.2010.12.006, 2011.

Lémond, J., Dandin, P., Planton, S., Vautard, R., Pagé, C., Déqué, M., Franchistéguy, L., Geindre, S., Kerdoncuff, M., Li, L., Moisselin, J.-M., Noël, T., and Tourre, Y.-M.: DRIAS: a step toward Climate Services in France, Adv. Sci. Res., 6, 179-186, doi:10.5194/asr-6-179-2011, 2011.

Lorenz, S., Dessai, S., Forster, P., and Paavola, J.: Tailoring the visual communication of climate projections for local adaptation practitioners in Germany and the UK, SRI Papers 81, Sustainability Research Institute, School of Earth and Environment, The University of Leeds, Leeds, 2015.

Ouzeau, G., Déqué, M., Jouini, M., Planton, S., and Vautard, R.: Scénarios régionalisés - édition 2014 - pour la métropole et les régions d'outre-mer. Le climat de la France au XXIe siècle, Volume 4, rapport de la mission Jean Jouzel, août 2014, Ministère de l'Ecologie, du Développement Durable, des Transports et du Logement, Paris, France, 62 pp., 2014.

Porter, J., Demeritt, D., and Dessai, S.: The Right Stuff? Informing Adaptation to Climate Change in British Local Government, SRI Papers 76, Sustainability Research Institute, School of Earth and Environment, The University of Leeds, Leeds, 2014.

Spence, A., Poortinga, W., Butler, C., and Pidgeon, N. F.: Perceptions of climate change and willingness to save energy related to flood experience, Nat. Clim. Change, 1, 46-49, 2011.

Stickdorn, M. and Schneider, J.: This is service design thinking, BIS publishers, Amsterdam, the Netherlands, 2010.

Weber, E. U.: What shapes perceptions of climate change?, Wiley Interdisciplinary Reviews: Climate Change, 1, 332-342, 2010. 